ARTICLE

DOI: $10.1038 / \mathrm{s} 41467-018-05781-6$

\title{
Discovery of cationic nonribosomal peptides as Gram-negative antibiotics through global genome mining
}

Yong-Xin Li,2, Zheng Zhong ${ }^{1}$, Wei-Peng Zhang ${ }^{1} \&$ Pei-Yuan Qian ${ }^{1}$

The worldwide prevalence of infections caused by antibiotic-resistant Gram-negative bacteria poses a serious threat to public health due to the limited therapeutic alternatives. Cationic peptides represent a large family of antibiotics and have attracted interest due to their diverse chemical structures and potential for combating drug-resistant Gram-negative pathogens. Here, we analyze 7395 bacterial genomes to investigate their capacity for biosynthesis of cationic nonribosomal peptides with activity against Gram-negative bacteria. Applying this approach, we identify two novel compounds (brevicidine and laterocidine) showing bactericidal activities against antibiotic-resistant Gram-negative pathogens, such as Pseudomonas aeruginosa and colistin-resistant Escherichia coli, and an apparently low risk of resistance. The two peptides show efficacy against $E$. coli in a mouse thigh infection model. These findings may contribute to the discovery and development of Gram-negative antibiotics.

\footnotetext{
${ }^{1}$ Department of Ocean Science and Division of Life Science, Hong Kong University of Science and Technology, Clear Water Bay, Hong Kong, China. ${ }^{2}$ Institute for Advanced Study, Hong Kong University of Science and Technology, Clear Water Bay, Hong Kong, China. These authors contributed equally: Yong-Xin Li, Zheng Zhong. Correspondence and requests for materials should be addressed to P.-Y.Q. (email: boqianpy@ust.hk)
} 
nfection due to multidrug-resistant Gram-negative bacteria has become a major threat to public health ${ }^{1,2}$. The worldwide search for a truly novel class of antibiotics that can combat such bacteria and overcome antibiotic resistance has continued for the last 40 years $^{1-4}$. Cationic peptides are found in all forms of life and are among the most widespread and structurally diverse antibiotics in nature. Carrying unique chemical properties that enable them to not only penetrate those outer membranes that are highly impermeable, but also interact with multiple anionic intracellular targets, cationic peptides are highly effective against drug-resistant Gram-negative pathogens ${ }^{5-9}$. In the past four decades, thousands of cationic peptides with broad antimicrobial activities have been identified with most of them being either natural or naturally-derived host-defense peptides from multicellular organisms. However, only a handful of these cationic peptides have entered clinical application, due to their high cost of supply, proteolytic instability, and unknown toxicological profile $\mathrm{e}^{8-14}$.

Global analysis of sequenced bacterial genomes indicates that nonribosomal peptides (NRPs) are among the most widespread and structurally diverse families of complex secondary metabolites, the vast majority of which encode unknown natural products ${ }^{15-17}$. Among these NRPs, cationic nonribosomal peptides (CNRPs) with their sufficient supply and proteolytic stability are attractive therapeutic candidates to combat Gram-negative pathogens. Polymyxins and gramicidin $\mathrm{S}$ produced by Bacilli bacteria are in fact among the few precedents with clinical efficacy ${ }^{12-14}$. However, the diversity and complexity of CNRPs have made systematic investigation difficult and consequently, the vast majority of genetically encoded CNRPs in bacteria have been overlooked.

In the present study, we adopt a global genome-mining approach to provide insight into the biosynthetic capacity of CNRPs and facilitate the genome-guided discovery of antibiotics (Fig. 1). By screening 7395 bacterial genomes for the potential biosynthesis of cationic nonribosomal peptides, we identify two novel peptides with activities against antibiotic-resistant Gramnegative pathogens.

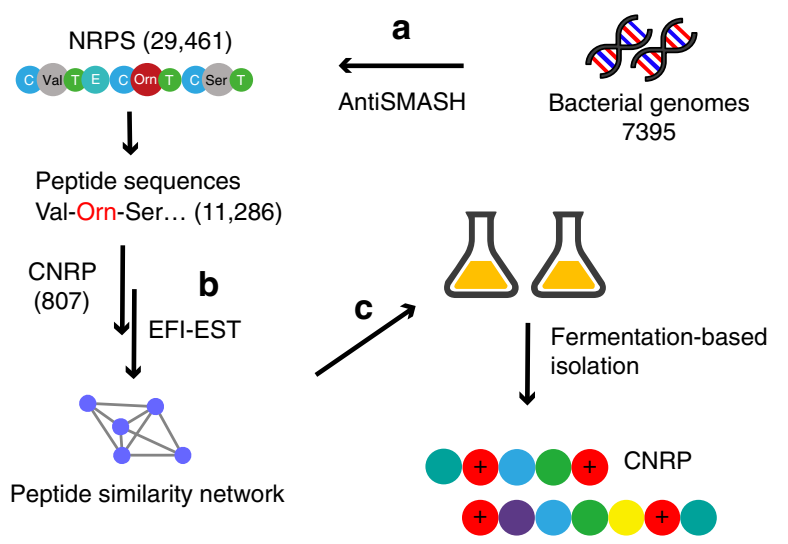

Fig. 1 Workflow of the global genome mining of CNRP BGCs. a 7395 complete or draft bacterial genomes were downloaded from GenBank and subjected to stand-alone antiSMASH for BGC analysis and NRP sequence prediction, leading to the identification of 29,461 NRPS BGCs, in which 11,286 BGCs encoded NRPs with positively charged residues. b Selected peptide sequences of cationic peptides (numbering 807 ) were submitted to the EFI-Enzyme Similarity Tool (EFI-EST) for constructing the peptide similarity network. c The CNRPs with desirable chemical features were obtained by conventional fermentation-based isolation

\section{Results}

Global analysis of genetically encoded CNRPs. Current genome-mining strategies rely heavily on comparing sequences with known biosynthetic genes or domains to identify orphan biosynthetic gene clusters (BGCs) ${ }^{17-19}$. Here, we developed a genome-mining approach based on antiSMASH ${ }^{19}$ that effectively targets NRP BGCs by parsing the chemical features of predicted NRPs rather than the sets of domains or protein sequences that are phylogenetically closely related (Fig. 1). To gain insight into the diversity of bacterial CNRPs, we bioinformatically analyzed 5585 complete bacterial genomes for BGCs encoding CNRPs. In total, 665 out of 6879 genetically encoded NRPs contained two or more positively charged amino acids (i.e., arginine, histidine, lysine, ornithine, and 2,4-diaminobutyric acid), which were mainly distributed in Proteobacteria, Actinobacteria, and Firmicutes (Supplementary Fig. 1). Further, draft genomes (numbering 1810) from the top 20 genera in terms of CNRP abundance as well as 5585 complete genomes were chosen for global genome mining of CNRPs. A total of 11,286 BGCs encoding NRPs with positively charged residues were detected from 7395 bacterial genomes. Of the 11,286 NRPs, 2801 were putative CNRPs containing two or more positively charged residues. This number is four times that generated from data sets of the complete bacterial genomes. Further, BGC analysis of these putative CNRPs excluding peptides with $\mathrm{N}$-formyl-N-OH-Lys/Orn residues (i.e., siderophores $)^{20}$ or shorter peptides led to the identification of 807 CNRPs ( $\geq 6$ residues and $\geq 2$ positively charged residues) that are extremely diverse and widely distributed in bacteria (Fig. 2). Most of these CNRPs (>95\%) varied from 6 to 18 in length with an average of 9.8 (median 9), while their percentage of positively charged residues ranged from 6.3 to $77.8 \%$ with an average of $30.6 \%$ (median 28.6\%) (Supplementary Fig. 2).

To obtain insight into the structural diversity and novelty of CNRPs, we next applied the EFI-Enzyme Similarity Tool $(\text { EFI-EST })^{21}$ to directly chart the chemical space of genetically encoded CNRPs using the predicted peptide sequence of chemical compounds rather than the sequence of proteins or domains as in previous methods ${ }^{18,22,23}$. A sequence similarity network ${ }^{21}$ consisting of 807 CNRPs as well as 24 known CNRPs was then constructed to visualize the diversity, distribution, and discovery status of CNRPs (Fig. 2). It immediately became clear that the majority of CNRPs were unexplored, with most of them mainly harbored by Proteobacteria and Firmicutes. Our analysis suggests that 793 out of the 807 predicted CNRPs did not have any isolated members. In particular, 738 could not be grouped into the known classes of CNRPs, reiterating our finding that the vast majority of genetically encoded CNRPs have yet to be discovered. The volume of bacterial genomic data is increasing by leaps and bounds every day. Our approach not only offers insight into the biosynthetic capacity of NRPs, but also enables identifying and prioritizing novel BGCs of interest within large data sets in a robust manner for the genomics-based discovery of natural products.

Leveraging structure prediction for CNRP discovery. We next sought to leverage network analysis-associated prioritization to facilitate the targeted, genome-guided discovery of novel CNRPs. $\mathrm{N}$-acylated CNRPs, also known as cationic lipopeptides including polymyxins and tridecaptins ${ }^{24}$, represent a growing family of attractive candidate antibiotics as they have shown high efficacy against infections caused by Gram-negative pathogens. Our global analysis suggests that 261 CNRPs (or 32.3\%) were putative cationic lipopeptides. Intriguingly, 254 (or 97.3\%) of them did not have any isolated members. In particular, 221 (or $84.7 \%$ ) could not be grouped into the known classes of CNRPs (Supplementary 


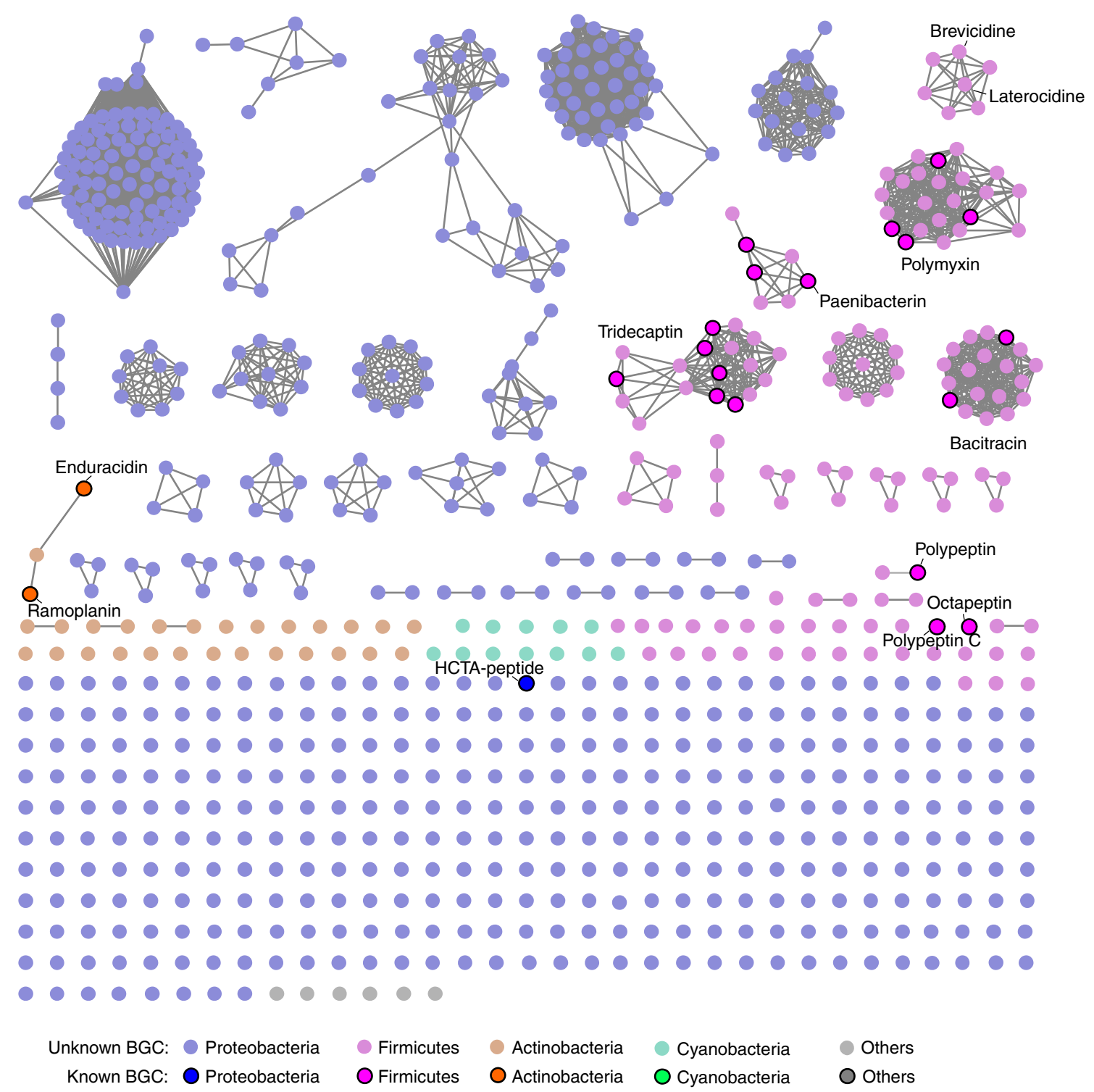

Fig. 2 A peptide similarity network of the CNRPs showing their diversity, distribution, and discovery status. Clearly, the majority of CNRPs remain unexplored, particularly the ones in the Firmicutes and Proteobacteria phyla

Figs. 3-4). These CNRPs therefore likely represent novel classes of cationic lipopeptides. Among these diverse BGCs for cationic lipopeptides, 116 falling into 12 classes were harbored by Bacilli. Since cryptic metabolites have proven to be a major bottleneck in genome-guided discovery, we selected Bacilli for the fermentation-based discovery of antibiotics as this class of bacteria are well known for producing CNRP antibiotics ${ }^{24}$. Traditional fermentation-based isolation was then performed focusing on putative cationic lipopeptides with three or more positively charged residues, as more positively charged residues enable electrostatic interaction with negatively charged cell membranes while the hydrophobic acyl chain defines membranolytic and cellpenetrating properties ${ }^{7}$.

Brevibacillus laterosporus DSM 25, ATCC 9141, and Paenibacillus alvei DSM 29 of the Bacilli that harbored active BGCs of interest on the basis of genome mining and metabolic analysis were selected for further study (Methods and Fig. 3a-b). Metabolic analysis of selected strains using UPLC-MS-ESI showed a typical ion pattern of cationic peptides (i.e., MW > 1000 and an abundance of doubly/triply charged ions) (Fig. 3c). Cationic lipopeptides (1-3) and their derivatives were subsequently isolated from three strain cultures and characterized structurally by MS/MS, NMR, and Marfey-type analyses (Fig. 3b and Supplementary Figs. 5-7). Compound 1 was obtained as a white amorphous solid from strain DSM 25. On the basis of HRESIMS data $\left(\mathrm{m} / z 760.4046[\mathrm{M}+2 \mathrm{H}]^{2+}\right.$, calculated 760.4064), we established its molecular formula to be $\mathrm{C}_{74} \mathrm{H}_{106} \mathrm{~N}_{18} \mathrm{O}_{17}$. The characteristic signals of the amide proton in the ${ }^{1} \mathrm{H}-\mathrm{NMR}$ spectrum and of carbonyl groups in the ${ }^{13} \mathrm{C}$ NMR spectrum (Supplementary Notes) indicated the peptidic nature of compound $\mathbf{1}$. The gross structure of $\mathbf{1}$ was further established by analyses of the ${ }^{1} \mathrm{H},{ }^{13} \mathrm{C},{ }^{1} \mathrm{H}-{ }^{1} \mathrm{H}$ COSY, HMQC, and HMBC NMR spectral data (Supplementary Fig. 5b), revealing the presence of Orn (3), Trp (2), Gly (2), Ile (1), Ser (1), Thr (1), Asn(1), Tyr (1), and a lipidic residue that was identified as 4-methylhexanoic acid. The gross structure established by NMR analysis was also corroborated by MS/MS analysis (Supplementary Fig. 5a). On the basis of advanced Marfey's analysis for the absolute configuration of amino acids (Supplementary Fig. 5c), a lipodepsipeptide 4Methyl-Hexanoyl-D-Asn-D-Tyr-D-Trp-D-Orn-Orn-Gly-D-OrnTrp-Thr-Ile-Gly-Ser (cyclized via lactone formation between $\mathrm{Thr}$ and the $\mathrm{C}$ terminus) was established for compound $\mathbf{1 .}$ 
a

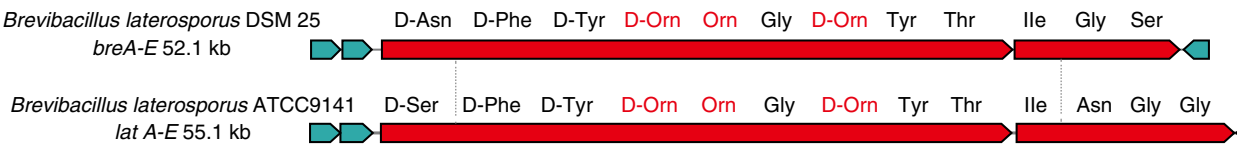

b

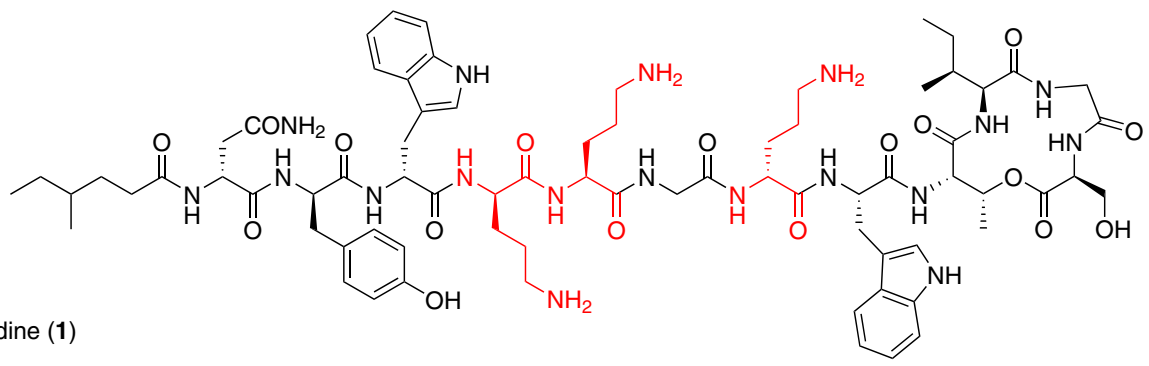

Brevicidine (1)

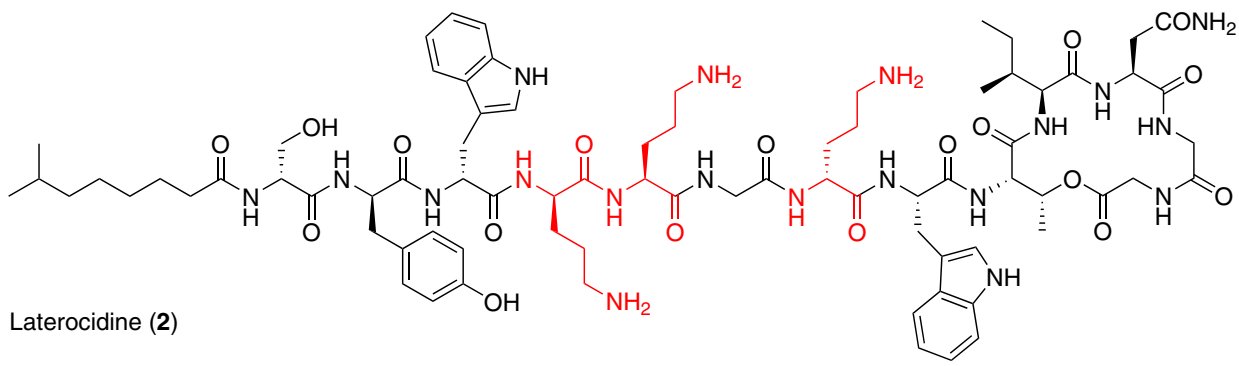

C
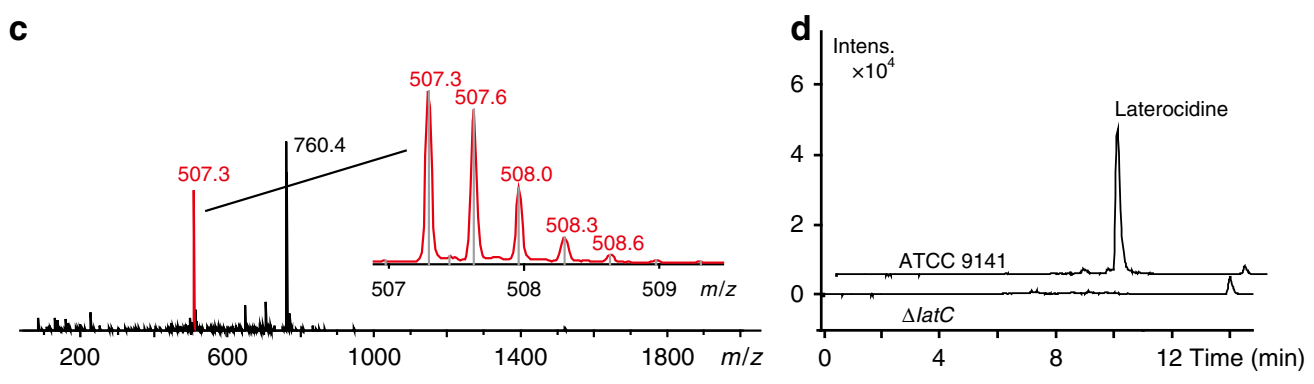

Fig. 3 Cationic antibacterial peptides discovered via global genome mining. a Two gene clusters of investigated cationic peptides, with amino acids incorporated. Cationic residues are marked in red. $\mathbf{b}$ Structure of isolated cationic peptides identified by MS/NMR analysis. Positively charged amino acids are highlighted in red. c Mass spectra (ESI) of cationic peptide brevicidine. $\mathbf{d}$ Liquid chromatography-mass spectrometry traces comparing $B$. laterosporus ATCC 9141 wild type and the $\Delta$ latC mutant. Figure $3 \mathbf{c}-\mathbf{d}$ are representative of three independent experiments

These newly identified CNRPs, named brevicidine (1), laterocidine (2), and paenibacterin B (3), are new cyclic depsipeptides with an $\mathrm{N}$-acylated side chain and a lactone ring that formed through the condensation of a C-terminal residue with a threonine (Thr) residue. Paenibacterin B is a new derivative of paenibacterin (Supplementary Fig. 7), which is a bactericidal antibiotic binding to the bacterial outer membrane ${ }^{25}$. Together with well-known peptide antibiotics including polymyxins, ramoplanin, and enduracidin, these CNRPs belong to a large family of cyclic cationic lipopeptides that are acylated at the $\mathrm{N}$ terminus by a lipid tail and cyclized between the $\mathrm{C}$ terminus and the internal residue with an amine or hydroxyl group via an amide or ester bond. Brevicidine and laterocidine form a new class of cyclic cationic peptides exhibiting two unique structural features: a linear cationic segment with three positively charged ornithine residues, and a small hydrophobic tetrapeptide/ pentapeptide ring (Fig. 3b). They are different from previously reported cyclic cationic lipopeptides that share the structural feature of a positively charged macro-ring (Supplementary Fig. 8).

Predicted biosynthesis of laterocidine started with a typical starting module for $\mathrm{N}$-acylated NRPs with a condensation starter domain that acylated the first amino acid with a fatty acid. In accordance with the co-linearity rule, the other 13 amino acids, including positively charged residues $\left(\mathrm{D}-\mathrm{Orn}_{4}, \mathrm{~L}-\mathrm{Orn}_{5}\right.$, and D$\mathrm{Orn}_{7}$ ), were introduced into the linear peptide and the ring closure between the last $\mathrm{Gly}_{13}$ and $\mathrm{Thr}_{9}$ was catalyzed by a thioesterase domain during product offloading (Supplementary Fig. 9). A similar biosynthetic assembly line was also adopted by brevicidine biosynthesis (Supplementary Fig. 10). To directly link the predicted CNRP BGCs to their isolated putative CNRPs, we applied the CRISPR/Cas9 gene editing system ${ }^{26-28}$ to generate a $\Delta$ latC mutant strain of Brevibacillus laterosporus ATCC 9141 for metabolic analysis. The complete abolishment of laterocidine production in the $\triangle$ latC mutant in UPLC-MS analysis (Fig. $3 \mathrm{~d}$ ) suggests gene cluster lat A-E to be the BGC of laterocidine, thus directly linking the CNRPs predicted from global genome mining to the isolated natural product. Altogether, our results demonstrate the power of global genome mining for the targeted, genome-guided discovery of novel CNRPs.

Antibiotic activity, resistance, and mechanism. All of the isolated compounds 1-11 (Supplementary Fig. 11) were assessed for bioactivities against ESKAPE bacteria (Enterococcus faecium, 
Staphylococcus aureus, Klebsiella pneumoniae, Acinetobacter baumannii, Pseudomonas aeruginosa, and Enterobacter species), which cause the majority of hospital-acquired infections ${ }^{2}$. Both brevicidine and laterocidine exhibited broad antibacterial activities against Gram-negative bacteria including opportunistic pathogens such as difficult-to-treat $P$. aeruginosa and colistinresistant E. coli. Minimal inhibitory concentration (MIC) values in the micromolar range $\left(1-16 \mu \mathrm{g} \mathrm{mL}^{-1} ; 0.66-10.5 \mu \mathrm{M}\right)$ testified to their high potency. Further, the antibacterial activities of compounds 1-2 were not impaired in the presence of fetal bovine serum (Table 1). Harboring unnatural amino acids such as Damino acids, a fatty acid side chain and a lactone ring, the two cyclic lipopeptides were proteolytically stable. Our preliminary structure-activity relationship study suggests that both the linear cationic segment and the hydrophobic lactone ring were crucial for their activities. For example, the lack of either the lactone ring or the cationic side chain dramatically increased MIC values 8- to 32-fold (1 vs. 4-5, 2 vs. 9-11) (Supplementary Table 1). The two CNRPs 1 and 2 were bactericidal against E. coli as revealed by the growth kinetics of $E$. coli, time-kill assay, and lysis assay (Fig. $4 \mathrm{a}-\mathrm{c}$ ). Both the time-kill assay and growth kinetics showed time-dependent reductions in the number of colony-forming units per $\mathrm{mL}$ (c.f.u. $\mathrm{mL}^{-1}$ ) or in the $\mathrm{OD}_{600}$ value for E. coli treated by compounds $\mathbf{1}-\mathbf{2}$. The $E$. coli cells were completely lysed at ten times the MIC, similar to polymyxin B. Compounds 1-2 neither caused the lysis of erythrocytes nor showed significant toxicity against the human cell line HeLa at concentrations up to $128 \mu \mathrm{g}$ $\mathrm{mL}^{-1}$ (Supplementary Fig. 12), suggesting that they are promising candidates for Gram-negative antibiotics.

To explore the mode of action of compounds 1-2, we initially attempted to identify resistant mutants of E. coli ATCC 25922. Interestingly, E. coli did not develop resistance during continuous serial passaging in the presence of subinhibitory concentrations of either 1 or 2 over a 30-day period (Fig. 4d), suggesting a low risk of resistance to compounds 1-2. By contrast, E. coli developed resistance to ciprofloxacin within only a few days of exposure (Fig. 4d). E. coli did not develop resistance to 1 either when plated on media at four times the MIC. Neither 1 nor $\mathbf{2}$ exhibited antibiotic effects when cells were grown in the presence of exogenous lipopolysaccharides (LPS) or a high concentration of

Table 1 Activity of CNRPs against microorganisms

\begin{tabular}{|c|c|c|c|c|}
\hline \multirow[t]{2}{*}{ Target species } & \multicolumn{4}{|c|}{ MIC $\left(\mu \mathrm{g} \mathrm{mL}^{-1}\right)$} \\
\hline & 1 & 2 & Polymyxin B & Colistin \\
\hline Escherichia coli ATCC 25922 & 2 & 2 & 1 & 2 \\
\hline Colistin-resistant E. coli a & 2 & 2 & 16 & 16 \\
\hline E. coli ATCC $25922+10 \%$ serum & $2-4$ & $2-4$ & $1-2$ & $2-4$ \\
\hline $\begin{array}{l}\text { E. coli ATCC } 25922+\mathrm{Mg}^{2+}(21 \\
\mathrm{mM})\end{array}$ & $>64$ & $>64$ & $>64$ & $>64$ \\
\hline $\begin{array}{l}\text { E. coli ATCC } 25922+\text { LPS }(1.0 \\
\left.\mathrm{mg} \mathrm{mL}^{-1}\right)\end{array}$ & $>64$ & $>64$ & $>64$ & $>64$ \\
\hline E. coli TOP10 & 2 & 2 & 2 & 2 \\
\hline Pseudomonas aeruginosa PAO1 & 1 & 2 & 1 & 1 \\
\hline Acinetobacter baumannii & 16 & 4 & 4 & \\
\hline $\begin{array}{l}\text { Klebsiella pneumoniae NRRL-B- } \\
408\end{array}$ & 2 & 4 & 16 & \\
\hline K. pneumoniae NRRL-B-3521 & 4 & 4 & 2 & \\
\hline Enterobacter cloacae NRRL-B-413 & 2 & 2 & 8 & \\
\hline E. cloacae NRRL-B-425 & 2 & 2 & 64 & \\
\hline Bacillus subtilis 168 & 32 & 32 & 4 & \\
\hline Candida albicans & $>64$ & $>64$ & $>64$ & \\
\hline Saccharomyces cerevisiae & $>64$ & $>64$ & $>64$ & \\
\hline Staphylococcus aureus (MRSA) & $>64$ & $>64$ & 32 & \\
\hline
\end{tabular}

$\mathrm{Mg}^{2+}$ as expected (Table 1), suggesting that these cationic peptides disrupted the integrity of the outer membrane through association with LPS. This suggestion was further supported by atomic force microscopy (AFM) and isothermal titration calorimetry analysis. AFM analysis of E. coli ATCC 25922 and $P$. aeruginosa PAO1 treated with compound $\mathbf{1}$ or $\mathbf{2}$ showed that treated cells lost their regular rod-like shape and became lumpy and rugged (Fig. 4e and Supplementary Figs. 13-14). The morphology of compound-treated cells was extensively disrupted as characterized by undulations on the order of $\sim 30 \mathrm{~nm}$ in amplitude, whereas untreated $E$. coli remained uniform. Indeed, compound 1 displayed high affinity for LPS in vitro (dissociation constant $K_{\mathrm{d}}$ of $6.5 \mu \mathrm{M}$ ), similar to polymyxin B (Supplementary Fig. 15). Notably, the antibacterial activities of both brevicidine and laterocidine were retained against colistin-resistant E. coli ATCC 25922 carrying $m c r-1$ (Table 1), suggesting that the action of the two CNRPs is independent of phosphoethanolamine modifications in lipid $\mathrm{A}^{29}$. Collectively, the data suggest that compounds 1-2 represent an attractive therapeutic alternative for combating drug-resistant Gram-negative bacteria expressing $m c r-1$, which poses a significant threat to public health worldwide.

The growth kinetics of $E$. coli cells showed that cells exposed to compound 1 or 2 grew at a reduced rate for $30 \mathrm{~min}$, after which a steady decrease in cell count was observed (Fig. 4a). These data are different from those of polymyxins, which are generally bactericidal within minutes of exposure due to the formation of large, nonspecific pores in the bacterial membrane ${ }^{30,31}$. In the time-kill assays, E. coli cells showed slightly reduced cell viability after $15 \mathrm{~min}$ of exposure and a significant reduction after $30 \mathrm{~min}$ of exposure to $\mathbf{1}$ or $\mathbf{2}$ at ten times the MIC. Polymyxin B acted more quickly, significantly reducing the viable cell population after $5 \mathrm{~min}$ and killing all cells within $30 \mathrm{~min}$. These results suggest that compounds 1-2 may be membrane-targeting bactericidal peptides but may not act through a generic membrane lysis mechanism-like polymyxin B does.

Studying the mode of action of cationic peptides is challenging because they have several modes of action, such that they are able to interact with multiple anionic intracellular targets. Take the well-studied cationic peptide polymyxins, for example, it is still unclear how they interact with and disrupt the cytoplasmic membrane and intracellular targets ${ }^{31,32}$. Although information on the mode of action of $\mathbf{1 - 2}$ is scant, the fact that no significant membrane disruption effect was observed at twice the MIC suggests that the two CNRPs could potentially have multiple targets. However, more in-depth mechanism study is needed to characterize their intracellular targets as well as their membrane disruption effect.

Given the low risk of resistance and the attractive mode of action of 1-2, an animal efficacy study was then performed in a mouse thigh model. Mice were intramuscularly infected with $1.50 \times 10^{6}$ c.f.u. of $E$. coli ATCC 25922 . Two hours post infection, brevicidine $\left(30 \mathrm{mg} \mathrm{kg}^{-1}\right)$ or laterocidine $\left(15 \mathrm{mg} \mathrm{kg}^{-1}\right)$ was subcutaneously injected at two doses. Levofloxacin $(\mathrm{MIC}=$ $0.032 \mu \mathrm{g} \mathrm{mL}^{-1}$ ) was dosed at $3.0 \mathrm{mg} \mathrm{kg}^{-1}$ as a positive control. The two compounds showed significant antibacterial efficacy against $E$. coli in the neutropenic mouse thigh infection model. In particular, compound $\mathbf{1}$ was highly efficacious in mice infected with $E$. coli and caused a $5 \log _{10}$ reduction in c.f.u. in the thigh compared to the vehicle control after $24 \mathrm{~h}$ (Fig. $4 \mathrm{f}$ ).

\section{Discussion}

The chemical diversity of natural cationic peptides has provided privileged scaffolds for the development of antibiotics to combat Gram-negative pathogens. These valuable metabolites are typically identified on a case-by-case basis, which is both tedious and 


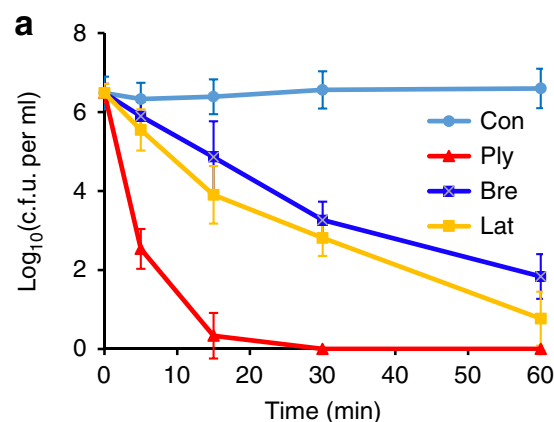

d

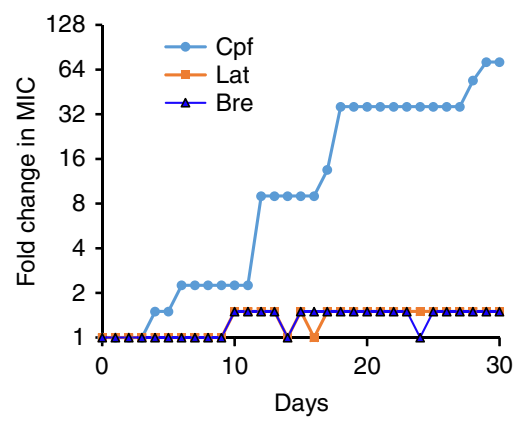

b

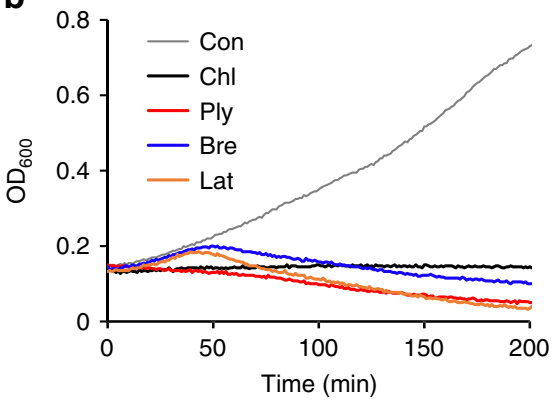

C

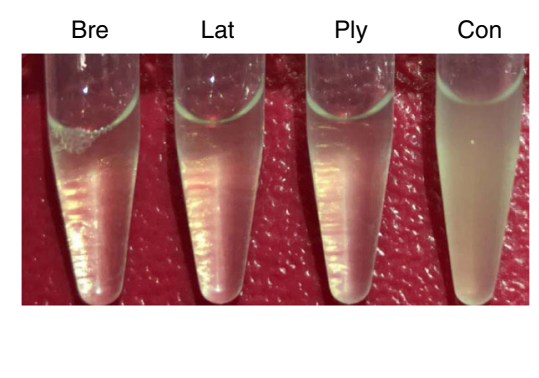

e

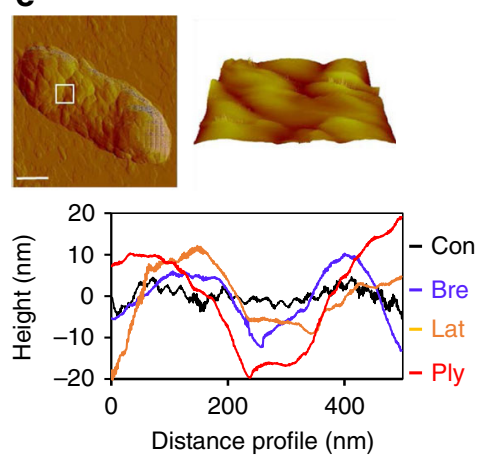

$\mathbf{f}$

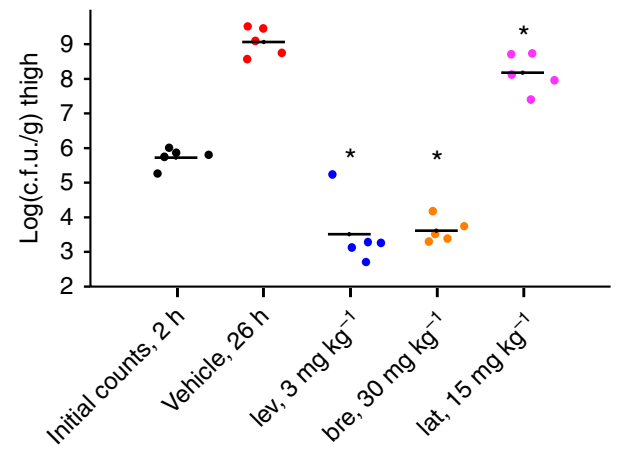

Fig. 4 Brevicidine and laterocidine show bactericidal activity, a low risk of resistance and efficacy in a mouse thigh infection model. a Time-kill assays. E. coli were grown to early phase and challenged with ten times the MIC of antibiotics. Data are representative of three independent experiments \pm s.d. $\mathbf{b}$ Bacterial growth kinetics. Optical densities of E. coli cells exposed to two times the MIC of antibiotics. c CNRP treatment resulted in the lysis of E. coli. Figures $\mathbf{b}$, $\mathbf{c}$ are representative of three independent experiments. $\mathbf{d}$ Resistance acquisition during serial passaging in the presence of sub-MIC levels of antimicrobials. e Atomic force microscopy of $E$. coli grown at $37^{\circ} \mathrm{C}$ to mid-log phase $\left(\mathrm{OD}_{600}\right.$ of $\left.\sim 0.5\right)$ in the presence of ten times the MIC of CNRP antibiotics. Scale bar is $1 \mu \mathrm{m}$. The white square highlights the region scanned to obtain high-resolution topographical images of the brevicidine-treated cell surface. Scans are representative of two independent experiments. $\mathbf{f}$ Efficacy of brevicidine and laterocidine in a mouse thigh model infected by E. coli. Brevicidine $\left(30 \mathrm{mg} \mathrm{kg}^{-1}\right.$ ) or laterocidine $\left(15 \mathrm{mg} \mathrm{kg}^{-1}\right.$ ) treatment (twice) of $E$. coli thigh infections (five mice) leads to a reduced number of viable bacteria after $26 \mathrm{~h}$. Significant differences between groups analyzed by the Mann-Whitney test $\left({ }^{\star} P<0.01\right)$. For a-f, con negative control, bre brevicidine, lat laterocidine, ply polymyxin, lev levofloxacin, chl chloramphenicol, and cfp ciprofloxacin

downright inefficient. Bioinformatics methods have recently been developed to prioritize and deduplicate the genome-based discovery of natural products from large data sets ${ }^{17-19,22}$. However, the structural and biosynthetic diversity of genetically encoded cationic peptides has rendered their comprehensive investigation and targeted discovery extremely challenging. Here, we systematically profiled the scaffolds of bacterial NRP-derived cationic peptides, by employing a peptide sequence similarity network to sort and target these cationic peptides on the basis of their chemical features. Using chemical building blocks of NRPs predicted by well-established algorithms, our network-associated genomemining approach provided us a rare chance to directly and rapidly examine the structures and functions of CNRPs. Our analysis not only revealed the chemical diversity of CNRPs in bacteria, but also prioritized a novel scaffold of interest for antibiotic discovery.

The increasing incidence of infection caused by multidrugresistant Gram-negative pathogens, especially colistin-resistant pathogens, threatens to overwhelm healthcare systems worldwide. Bacteria harboring the colistin-resistant gene $m c r-1$ have been found across the globe since their first discovery in $2015^{29,33}$. These bacteria threaten to remove the antibiotics of last resort from an already shrinking antibiotic arsenal. New antibacterial candidates with a low risk of resistance are urgently needed as conventional antibiotics are quickly becoming ineffective as a result of resistance. The present study highlights the utility of global genome mining in the systematic investigation of bacterial CNRPs and provides a tool for the targeted discovery of CNRP antibiotics. Making use of this tool and its structural prediction and prioritization capabilities, we identified two new classes of cationic antibiotics. The successful demonstration of the antimicrobial efficacy of two CNRPs against Gram-negative pathogens, especially colistin-resistant pathogens, undoubtedly distinguishes bacterial CNRPs as a new source of Gram-negative antibiotics. However, like other cationic peptides, the mode of action and toxicity of these two CNRPs must be studied in greater detail to consolidate their status as promising preclinical antibiotic candidates. Our identification of antibiotics against Gramnegative bacteria through the global genome mining of CNRPs validates the power of this strategy in discovering suitable drug candidates to combat Gram-negative pathogens that have developed antibiotic resistance. It is likely that many other cationic peptide antibiotics with high efficacy and low resistance risk are present in bacteria and are just waiting to be discovered.

\section{Methods}

Global genome mining of CNRPs. A total of 5585 complete bacterial genomes (with cutoff on October 20, 2016) were retrieved from NCBI Genome and subjected to BGC analysis utilizing the stand-alone version of antiSMASH v3.0.5 ${ }^{34}$. In total, 6879 NRP BGCs were identified from complete bacterial genomes spanning the entire domain of bacteria. To gain insight into the biosynthetic capacity of bacterial CNRPs, we created a series of scripts to collect BGC information from the antiSMASH-annotated files. Costume Node.js scripts were prepared to extract 
predicted amino acid building blocks from adenylation (A) domains in nonribosomal peptide synthetase (NRPS). Amino acids predicted by Stachelhaus code were collected, and the frequency of occurrence in each NRPS gene cluster was determined. After analyzing all complete genomes, the genera were ranked based on their abundance in CNRP BGCs containing two or more positively charged amino acids (i.e., arginine, histidine, lysine, ornithine, and 2,4-diaminobutyric acid). Draft genomes (numbering 1810) from the top 20 genera as well as all complete genomes were chosen for global genome mining of CNRPs. The top 20 genera were Actinoplanes, Alcanivorax, Arthrobacter, Azotobacter, Bacillus, Brevibacillus, Corallococcus, Cyanothece, Kibdelosporangium, Myxococcus, Nitrosomonas, Paenibacillus, Pandoraea, Photorhabdus, Polyangium, Pseudomonas, Saccharothrix, Sorangium, Vibrio, and Xenorhabdus. Peptide sequence similarity networking was performed using the EFI-EST ${ }^{21}$. In total, 7395 bacterial genomes were subjected to BGC analysis, leading to the identification of 29,461 NRP BGCs. Gene clusters containing protein SMCOG1080 (lysine/ornithine $N$-monooxygenase) were excluded from this study because their encoding products were mainly NRPS-dependent siderophores with $N$-formyl-N-OH-Lys/Orn residues ${ }^{20}$ Costume Node.js scripts were developed to interrogate the predicted peptide sequences and convert the amino acids into their abbreviated forms. Nonproteinogenic amino acids were assigned to their proteinogenic counterparts based on their structural similarity or biosynthesis origin (Supplementary Table 2). The peptide sequences of all gene clusters were filtered according to the following rules: number of positively charged amino acids $(\mathrm{K}, \mathrm{H}$, and $\mathrm{R}) \geq 2$ and sequence length $\geq 6$. In total, 807 peptide sequences were selected and analyzed by EFI-EST ( $E$ value $=10 \mathrm{E}-3$, Fraction $=1$ ). The resulting full network was visualized by Cytoscape $^{35}$. In particular, the polymyxin family contains an extremely high proportion of Dab and a limited amino acid composition, which can lead to an inaccurate $E$ value in EFI-EST. Thus, the polymyxin family (23 BGCs) was manually selected and analyzed separately using BLASTP multiple alignment to construct the network $(E$ value $<10 \mathrm{E}-3)$.

Metabolic analysis by UPLC-MS. On the basis of global genome mining targeting those $\mathrm{N}$-acylated CNRPs with three or more positively charged residues, our follow-up screening focused on CNRPs in the Bacilli class which harbors the BGC group of polymyxins, tridecaptins, paenibacterins, or a putative new CNRP class (Supplementary Fig. 4). Six strains available in the bacterial collection center were selected for further metabolic analysis. B. laterosporus DSM 25 and ATCC 9141 harbor novel BGCs for a putative new class of CNRPs. P. polymyxa CICC 10580 and ATCC 842 harbor uncharacterized tridecaptin gene clusters, P. alvei DSM 29 harbors uncharacterized paenibacterin BGCs, and P. assamensis DSM 18201 harbors uncharacterized polymyxin BGCs. All of them could potentially produce new analogs of known peptide antibiotics on the basis of amino acid variation.

The six selected strains were cultivated in $5 \mathrm{~mL}$ of a modified Tryptic soy broth medium (MTSB, $30 \mathrm{~g} \mathrm{~L}^{-1}$ Tryptic Soy Broth (Sigma), $20.0 \mathrm{~g} \mathrm{~L}^{-1}$ starch $2.0 \mathrm{~g} \mathrm{~L}^{-1}$ $\mathrm{MgSO}_{4} \cdot 7 \mathrm{H}_{2} \mathrm{O}, 10.0 \mathrm{~g} \mathrm{~L}^{-1} \mathrm{CaCO}_{3}$ ) and then incubated at 30 or $37^{\circ} \mathrm{C}$ on a shaker $(250 \mathrm{rpm})$. After incubation for $12-48 \mathrm{~h}$, each culture supernatant was extracted with Diaion ${ }^{\oplus}$ HP-20 (0.25 g; Sigma-Aldrich) and washed with $20 \%$ isopropyl alcohol (IPA) $(4.0 \mathrm{~mL})$ and then eluted with $80 \%$ IPA supplemented with $0.1 \%$ trifluoroacetic acid $(0.50 \mathrm{~mL})$. The collected partition was dried and redissolved in $100 \mu \mathrm{L}$ of $\mathrm{MeOH}$ for metabolic analysis. The metabolic analysis of all samples dissolved in $100 \mu \mathrm{L}$ of $\mathrm{MeOH}$ was conducted on an ultra-high-performance liquid chromatography (UPLC) system (Waters ACQUITY, with a Waters BEH C18 reversed-phase UPLC column) coupled with a Bruker microTOF-q II mass spectrometer (Bruker Daltonics GmbH, Bremen, Germany). UPLC-MS analysis of the selected strains led to the identification of B. laterosporus DSM 25, ATCC 9141, and $P$. alvei DSM 29, which produced putative cationic peptides with the typical ion pattern (i.e., MW > 1000 and abundant doubly/triply charged ions).

Isolation of compounds. B. laterosporus DSM 25 was cultivated for 1 day at $30^{\circ} \mathrm{C}$ in five $2.5 \mathrm{~L}$ flasks containing $1.0 \mathrm{~L}$ of MTSB for brevicidine production. The culture supernatant was extracted with Diaion ${ }^{\circledR}$ HP-20 (100 g; Sigma-Aldrich) and eluted with $20 \%$ IPA $(2.0 \mathrm{~L}), 40 \%$ IPA (2.0 L), 60\% IPA (2.0 L), and $80 \%$ IPA supplemented with $0.1 \%$ trifluoroacetic acid $(1.0 \mathrm{~L})$. All partitions were evaporated to dryness using a vacuum concentrator and dissolved in methanol for HPLC purification. The $60 \%$ IPA partition was separated using a semi-preparative RPHPLC column with a gradient of $20-50 \% \mathrm{MeCN}$ in water to yield compounds 1 (25.0 mg, $5.0 \mathrm{mg} \mathrm{L}^{-1}$ ) and 4-6. B. laterosporus ATCC 9141 was cultivated for 2 days at $27^{\circ} \mathrm{C}$ in ten flasks with a volume of $2.5 \mathrm{~L}$ containing $1.0 \mathrm{~L}$ of MTSB for laterocidine (2) production. The culture supernatant was extracted with Diaion ${ }^{\circledast}$ HP-20 (100 g) and eluted with 20\% IPA (2.0 L), 40\% IPA (2.0 L), 60\% IPA (2.0 L), and $80 \%$ IPA supplemented with $0.1 \%$ trifluoroacetic acid $(1.0 \mathrm{~L})$. The last two partitions were evaporated to dryness and loaded into a C-18 column, then eluted with $120 \mathrm{~mL}$ of $30,50,60,70,80,90$, and $100 \%$ methanol, and $99 \%$ methanol supplemented with $1 \%$ trifluoroacetic acid. The $50 \%$ methanol partition was evaporated to dryness and separated using a semi-preparative RP-HPLC column with a gradient of $20-50 \% \mathrm{MeCN}$ in water to yield compounds $2\left(4.7 \mathrm{mg}, 0.47 \mathrm{mg} \mathrm{L}^{-1}\right)$ and $\mathbf{8}-10$.
Structure elucidation. ${ }^{1} \mathrm{H},{ }^{1} \mathrm{H}-{ }^{1} \mathrm{H}-\mathrm{COSY},{ }^{1} \mathrm{H}-{ }^{13} \mathrm{C}-\mathrm{HSQC}$, and ${ }^{1} \mathrm{H}-{ }^{13} \mathrm{C}-\mathrm{HMBC}$ NMR spectra for compounds $\mathbf{1}, \mathbf{2}$, and $\mathbf{4}$ were recorded on a Bruker AV500 spectrometer $(500 \mathrm{MHz})$ using MeOH- $d_{4}\left({ }^{1} \mathrm{H}-\mathrm{NMR} \mathrm{MeOH}-d_{4}: \delta_{\mathrm{H}}=3.31\right.$ ppm; MeOH- $d_{4}: \delta_{\mathrm{C}}=49.00 \mathrm{ppm}$ ). Amino acid configurations of 1-2 were determined using the advanced Marfey's method ${ }^{36}$. To further confirm the amino acid configurations of compounds 1-2, the D-Orn/Lys-specific hydrolysis of 1-2 was performed at $37^{\circ} \mathrm{C}$ for $2 \mathrm{~h}$ in $25 \%$ phosphate-buffered saline (PBS, pH 7.4, $80 \mu \mathrm{L}$ ) with $100 \mathrm{nM}$ D-Orn/Lys-specific peptidase BogQ ${ }^{28}$ and $100 \mu \mathrm{M}$ substrates (1-2). Three volumes of cold methanol $(240 \mu \mathrm{L})$ were added to the samples, which were then incubated at $-80^{\circ} \mathrm{C}$ for $1 \mathrm{~h}$ to precipitate protein. The samples were centrifuged at $21,500 \times g$ for $10 \mathrm{~min}$, and the supernatant $(2 \mu \mathrm{L})$ was injected into the same UPLC-MS system as the one described above. The BogQ hydrolyzed fragments of $\mathbf{1}$ and $\mathbf{2}$ were purified using the semi-preparative RP-HPLC column with $25 \% \mathrm{MeCN}$ in water supplemented with $0.1 \%$ trifluoroacetic acid to yield compounds 4-7 and 7-10. The purified compounds 1-2 and 4-10 (0.1-0.2 mg) were hydrolyzed in $6 \mathrm{M} \mathrm{HCl}$ at $120^{\circ} \mathrm{C}$ overnight. Each solution was evaporated to dryness under a stream of dry $\mathrm{N}_{2}$ and the residue was dissolved in $100 \mu \mathrm{L}$ of water and divided into two portions. Each portion was treated with $5 \mu \mathrm{L}$ of $\mathrm{NaHCO}_{3}(1$ $\mathrm{M})$ and $50 \mu \mathrm{L}$ of 1-fluoro-2, 4-dinitrophenyl-5-L-leucinamide (L-FDLA) or DFDLA $(1 \mathrm{M})$ at $40^{\circ} \mathrm{C}$ for $2 \mathrm{~h}$. The reaction was quenched with $5 \mu \mathrm{L}$ of $\mathrm{HCl}(1 \mathrm{M})$ and diluted with $200 \mu \mathrm{L}$ of $\mathrm{MeOH}$. The stereochemistry was determined by comparing the L-/D FDLA derivatized samples using UPLC-MS analysis.

Antibacterial assays. MIC was determined by broth microdilution according to CLSI guidelines. The test medium for most species was Mueller-Hinton broth (MHB). Bacteria were grown overnight to early stationary phase and adjusted in MHB to $5.0 \times 10^{5}$ c.f.u. $\mathrm{mL}^{-1}$ in the wells of 96 -well microtiter plates (Falcon ${ }^{\circledR} 96$ Well Flat-Bottom Microplate, Tissue Culture-Treated), mixed with varying concentrations of test compounds and incubated at $37^{\circ} \mathrm{C}$ for $24 \mathrm{~h}$. Cell growth was evaluated by measuring the optical density at $595 \mathrm{~nm}$ (Thermo Scientific Multiskan FC multiplate photometer) (Waltham, MA, USA), and the MIC was defined as the lowest compound concentration at which no bacterial growth was observed. MHBs containing $10 \%$ fetal bovine serum (Gibco), $21 \mathrm{mM} \mathrm{MgCl}$, or $1.0 \mathrm{mg} \mathrm{mL}^{-1} \mathrm{LPS}$ (lipopolysaccharides from E. coli O55:B5, Sigma-Aldrich) was used to test their inhibitory effects.

Bacterial growth kinetics and time-kill assay. A single fresh colony of $E$. coli TOP10 cells was inoculated into MHB $(5 \mathrm{~mL})$ and grown with shaking at $225 \mathrm{rpm}$ overnight. The bacteria were diluted to $1 \times 10^{5}$ c.f.u. $\mathrm{mL}^{-1}$ in fresh MHB, grown overnight to early log-phase $\left(\mathrm{OD}_{600}=0.15\right)$ and treated with the antibiotics of interest in the wells of a 96-well plate. Final antibiotic concentrations varied from one to eight times the MIC. The plate was then incubated at $30^{\circ} \mathrm{C}$ overnight, with $\mathrm{OD}_{600}$ measurements taken every $30 \mathrm{~s}$.

An overnight culture of $E$. coli TOP10 cells was diluted 1:10,000 in MHB and incubated at $37^{\circ} \mathrm{C}$ with agitation at $180 \mathrm{rpm}$ for $2 \mathrm{~h}$ (early exponential). The bacteria were then challenged with brevicidine $\left(20 \mu \mathrm{g} \mathrm{mL}^{-1}\right)$, laterocidine $(20 \mu \mathrm{g}$ $\left.\mathrm{mL}^{-1}\right)$, or polymyxin $\mathrm{B}\left(10 \mu \mathrm{g} \mathrm{mL}^{-1}\right)$ at ten times the MIC at room temperature without shaking. An untreated sample of cells was used as a negative control. At intervals, $10 \mu \mathrm{L}$ aliquots were removed, centrifuged at $10,000 \times g$ for $1 \mathrm{~min}$ and resuspended in $1.0 \mathrm{~mL}$ of sterile PBS. Tenfold serially diluted suspensions were plated on MHB agar plates and incubated at $37^{\circ} \mathrm{C}$ overnight. Colonies were counted and the number of c.f.u. per $\mathrm{mL}$ was calculated. For analysis of lysis, 300 $\mu \mathrm{L}$ of culture $\left(\mathrm{OD}_{600}=1.0\right)$ were treated with antibiotics at ten times the MIC for $24 \mathrm{~h}$. Experiments were performed in triplicate.

Resistance studies. E. coli ATCC 25922 was inoculated into MHB overnight at 37 ${ }^{\circ} \mathrm{C}$ with continuous shaking. Cells were diluted 10,000 times in MHB to about $1 \times$ $10^{6}$ c.f.u. $\mathrm{mL}^{-1}$. Ten $\mu \mathrm{L}$ aliquots were drawn to a 96 -well plate containing $90 \mu \mathrm{L}$ of serially diluted brevicidine, laterocidine, and ciprofloxacin, at final concentrations of $0.5 \times, 1 \times, 1.5 \times, 2 \times$, and $4 \times$ MIC. Likely due to the bactericidal effects of brevicidine and laterocidine, bacteria could not grow at higher MICs. Plates with bacteria were incubated at $37^{\circ} \mathrm{C}$ without shaking. After $24 \mathrm{~h}$, the MIC was recorded, and $1 \mu \mathrm{L}$ aliquots from the culture with the second-highest antibiotic concentration that showed visible growth were diluted 1000 times in MHB for the subsequent assay. This process was repeated for 30 days, and the final MIC was confirmed by the same antibacterial assay as the one described above. The experiment was performed in quadruplicate, and on each day, the sample that developed the highest resistance was measured to plot the curve. For single-step resistance, E. coli ATCC 25922 cells at $10^{8}$ c.f.u. were plated onto Mueller-Hinton agar containing $4 \times$ MIC of brevicidine. After incubation for $48 \mathrm{~h}$ at $37^{\circ} \mathrm{C}$, no resistant colonies were detected.

Cytotoxicity and hemolytic activity. Human HeLa cells were used in the assay. Ninety $\mu \mathrm{L}$ of $1 \times 10^{5} \mathrm{~mL}^{-1}$ cells were placed into the wells of 96 -microwell plates. After $12 \mathrm{~h}, 10 \mu \mathrm{L}$ of a medium containing test compounds at various concentrations were added to the cells which were then incubated at $37^{\circ} \mathrm{C}$ for $48 \mathrm{~h}$. Afterward, the supernatant was removed and $20 \mu \mathrm{L}$ of MTT (3-(4,5-Dimethylthiazol-2yl)-2,5-Diphenyltetrazolium Bromide) $\left(2.5 \mathrm{mg} \mathrm{mL}^{-1}\right)$ in PBS were added to each well. After incubation at $37^{\circ} \mathrm{C}$ for $3 \mathrm{~h}, 80 \mu \mathrm{L}$ of dimethyl sulfoxide (DMSO) were 
added to each well and incubated for an additional $15 \mathrm{~min}$. The absorbance was then measured at $570 \mathrm{~nm}$ with a Thermo Scientific Multiskan FC multiplate photometer.

Hemolytic activity was determined with red blood cells freshly isolated from healthy rabbits. Brevicidine and laterocidine were added at final concentrations of $128,64,32$, and $16 \mu \mathrm{g} \mathrm{mL}^{-1}$ in $0.5 \%$ DMSO to $2 \%(\mathrm{v} / \mathrm{v})$ erythrocytes in PBS. The cells were incubated for $1 \mathrm{~h}$ at $37^{\circ} \mathrm{C}$ and centrifuged for $5 \mathrm{~min}$ at $10,000 \times g$. The supernatant was transferred to a 96 -well plate and the absorbance was measured at a wavelength of $570 \mathrm{~nm}$ with a Thermo Scientific Multiskan FC multiplate photometer. The absorbance relative to the positive control, which was treated with $10 \%$ Triton X-100, was defined as the percentage of hemolysis.

Peptide binding to LPS. Microcalorimetric experiments of peptide binding to LPS were performed on an MCS isothermal titration calorimeter (Microcal, Northampton, MA) at $37^{\circ} \mathrm{C}$. LPS was prepared as a $50 \mu \mathrm{M}$ aqueous suspension in $20 \mathrm{mM}$ HEPES buffer ( $\mathrm{pH}$ 7.0) by suspension, sonication, and temperature cycling between 5 and $70^{\circ} \mathrm{C}$. This suspension was stored at $4{ }^{\circ} \mathrm{C}$ overnight prior to use. Aliquots of $100 \mu \mathrm{M}$ peptide solutions (brevicidine and polymyxin B) were prepared in the same buffer and all solutions were degassed prior to use by stirring under vacuum for 5 $\min$ at $37^{\circ} \mathrm{C}$. After thermal equilibration, $5 \mu \mathrm{L}$ aliquots of the peptide solution were added every $3 \mathrm{~min}$ into the lipid-containing cell at $37^{\circ} \mathrm{C}$ with constant stirring. The change in heat during the titration steps was registered in real time and raw data were processed using the Origin ${ }^{\circledR} 7$ software provided with the instrument. In control experiments, the corresponding peptide solution (or LPS solution) was injected into the buffer without LPS (or without peptide). Heats of dilution were significantly lower than those during ligand-receptor binding.

Atomic force microscopy imaging of bacterial cells. One hundred $\mu \mathrm{L}$ of $\log$ phase $E$. coli ATCC 25922 cells $\left(\mathrm{OD}_{600}=0.2\right)$ in an LB medium were incubated for $1.5 \mathrm{~h}$ at $37^{\circ} \mathrm{C}$ with or without the test compounds at ten times the MIC. The samples were then centrifuged at $8000 \times g$ for $10 \mathrm{~min}$ at $4{ }^{\circ} \mathrm{C}$, and the pellet was washed twice in $100 \mu \mathrm{L}$ of apyrogenic water. The bacteria resuspended in $50 \mu \mathrm{L}$ of apyrogenic water were applied to mica disks and dried overnight at $28^{\circ} \mathrm{C}$ before imaging. Atomic force micrographs were recorded on a Veeco Mulitmode AFM with NanoScope III controller operating in contact mode. The data were analyzed with NanoScope Analysis software v.1.40 (Veeco, USA). Scans were acquired at 25 ${ }^{\circ} \mathrm{C}$ at the rates of $1.0 \mathrm{~Hz}$ and 256 samples per line resolution. Downstream image processing and analysis were performed using NanoScope software. Height images were flattened to compensate for cell curvature, and topographical sections were used to reconstruct the surface texture in two dimensions.

Mouse thigh infection model. In vivo activities of brevicidine and laterocidine were tested using the mouse thigh infection model ${ }^{37}$. Animal studies were performed by Pharmacology Discovery Services Taiwan Ltd. in general accordance with standard guidelines on animal welfare ${ }^{38}$ in an AAALAC-accredited facility. The protocol was reviewed and approved by the Institutional Animal Care and Use Committee. Groups of five female-specific pathogen-free ICR (CD-1) mice weighing $22 \pm 2 \mathrm{~g}$ ( $\sim 5$ weeks of age) were used. Animals were immunosuppressed with two intraperitoneal injections of cyclophosphamide, the first at $150 \mathrm{mg} \mathrm{kg}^{-1}$ 4 days before infection (day -4 ) and the second at $100 \mathrm{mg} \mathrm{kg}^{-1} 1$ day before infection (day -1$)$. On day 0 , animals were inoculated intramuscularly $(0.1 \mathrm{~mL}$ per thigh) in the right thigh with an E. coli ATCC 25922 suspension. Vehicle (10\% DMSO, $1 \%$ Tween $80,0.9 \% \mathrm{NaCl}$ ) and antibiotics were then subcutaneously injected 2 and $8 \mathrm{~h}$ later. Due to the limited availability of compounds 1-2, only one concentration of $1\left(30 \mathrm{mg} \mathrm{kg}^{-1}\right)$ or $2\left(15 \mathrm{mg} \mathrm{kg}^{-1}\right)$ was used in the present study. Precisely $26 \mathrm{~h}$ after inoculation, animals were euthanized by $\mathrm{CO}_{2}$ asphyxiation before their right thigh muscles were harvested. The removed muscles were homogenized in $5 \mathrm{~mL}$ of PBS, pH 7.4, with a Polytron homogenizer. Homogenates in the amount of $0.1 \mathrm{~mL}$ were used for serial tenfold dilutions and plated onto a nutrient agar medium for colony count (in c.f.u. $\mathrm{g}^{-1}$ ) determination. No randomization or blinding was necessary for the animal infection models, and no samples were excluded.

\section{Gene deletion using the CRISPR-Cas9 system. Vector pJOE8999-latC was} constructed for deleting gene latC in the chromosome of B. laterosporus ATCC 9141 using the CRISPR-Cas9 system ${ }^{26-28}$. In the first step, the plasmid pJOE8999 was cut with $B s a \mathrm{I}$ and the lac $Z$ a fragment was replaced by the two complementary oligonucleotides $L a t C$-sgRNA-F/R. In the second step, two fragments flanking latC $\sim 400$ bp in length were amplified by polymerase chain reaction (PCR) using primers LatC-Up-F/R and LatC-41-Do-F/R from B. laterosporus ATCC 9141 chromosomal DNA as the template, and then cut with SfiI and inserted between the two Sfil sites to give pJOE8999-latC. Plasmid pJOE8999-latC was transformed into $B$. laterosporus ATCC 9141 according to a modified electroporation method ${ }^{28}$. Briefly, these competent cells mixed with $200 \mathrm{ng}$ of the pJOE8999-latC vector DNA were pulsed using a Gene-Pulser electroporation system and then plated on selective LB agar plates containing $25 \mathrm{mg} \mathrm{L}^{-1}$ kanamycin and $0.2 \%$ mannose for induction of cas 9 . The positive transformants were then inoculated at $22^{\circ} \mathrm{C}$ for 2 days on selective LB agar plates. The positive colonies with knockout vector were streaked onto LB plates without antibiotics and incubated at $45^{\circ} \mathrm{C}$ for plasmid curing. The colonies cured of plasmids were confirmed by streaking them onto LB plates containing kanamycin $\left(25 \mathrm{mg} \mathrm{L}^{-1}\right)$, where they failed to grow at $37^{\circ} \mathrm{C}$. The mutant colonies without plasmid were confirmed by colony PCR using the outer primers from the homology templates.

Code availability. Scripts for BGC analysis and networking analysis are provided in Supplementary Data 1.

Data availability. All data sets generated or analyzed in the current study have either been included in this published article (and its Supplementary Information files) or are available from the corresponding author on request.

Received: 5 April 2018 Accepted: 25 July 2018

Published online: 16 August 2018

\section{References}

1. Laxminarayan, R. et al. Antibiotic resistance-the need for global solutions. Lancet Infect. Dis. 13, 1057-1098 (2013).

2. Boucher, H. W. et al. Bad bugs, no drugs: no ESKAPE! An update from the Infectious Diseases Society of America. Clin. Infect. Dis. 48, 1-12 (2009).

3. Fischbach, M. A. \& Walsh, C. T. Antibiotics for emerging pathogens. Science 325, 1089-1093 (2009).

4. Lewis, K. Platforms for antibiotic discovery. Nat. Rev. Drug Discov. 12, 371-387 (2013).

5. Yeung, A. T. Y., Gellatly, S. L. \& Hancock, R. E. W. Multifunctional cationic host defence peptides and their clinical applications. Cell Mol. Life Sci. 68, 2161-2176 (2011).

6. Hancock, R. E. W. \& Lehrer, R. Cationic peptides: a new source of antibiotics. Trends Biotechnol. 16, 82-88 (1998).

7. Epand, R. M. \& Vogel, H. J. Diversity of antimicrobial peptides and their mechanisms of action. Biochim. Biophys. Acta Biomembr. 1462, 11-28 (1999).

8. Marr, A. K., Gooderham, W. J. \& Hancock, R. E. W. Antibacterial peptides for therapeutic use: obstacles and realistic outlook. Curr. Opin. Pharmacol. 6, 468-472 (2006).

9. Hancock, R. E. W. \& Sahl, H. G. Antimicrobial and host-defense peptides as new anti-infective therapeutic strategies. Nat. Biotechnol. 24, 1551-1557 (2006).

10. Kosikowska, P. \& Lesner, A. Antimicrobial peptides (AMPs) as drug candidates: a patent review (2003-2015). Expert Opin. Ther. Pat. 26, 689-702 (2016).

11. Fjell, C. D., Hiss, J. A., Hancock, R. E. W. \& Schneider, G. Designing antimicrobial peptides: form follows function. Nat. Rev. Drug Discov. 11, 37-51 (2012)

12. Mahlapuu, M., Hakansson, J., Ringstad, L. \& Bjorn, C. Antimicrobial peptides: an emerging category of therapeutic agents. Front. Cell Infect. Microbiol. 6, 194 (2016).

13. Law, V. et al. DrugBank 4.0: shedding new light on drug metabolism. Nucleic Acids Res. 42, D1091-D1097 (2014).

14. Gordon, Y. J., Romanowski, E. G. \& McDermott, A. M. A review of antimicrobial peptides and their therapeutic potential as anti-infective drugs. Curr. Eye Res. 30, 505-515 (2005).

15. Clardy, J., Fischbach, M. A. \& Walsh, C. T. New antibiotics from bacterial natural products. Nat. Biotechnol. 24, 1541-1550 (2006).

16. Schwarzer, D., Finking, R. \& Marahiel, M. A. Nonribosomal peptides: from genes to products. Nat. Prod. Rep. 20, 275-287 (2003).

17. Donia, M. S. et al. A systematic analysis of biosynthetic gene clusters in the human microbiome reveals a common family of antibiotics. Cell 158, 1402-1414 (2014).

18. Medema, M. H. \& Fischbach, M. A. Computational approaches to natural product discovery. Nat. Chem. Biol. 12, 639-648 (2015).

19. Blin, K., Medema, M. H., Kottmann, R., Lee, S. Y. \& Weber, T. The antiSMASH database, a comprehensive database of microbial secondary metabolite biosynthetic gene clusters. Nucleic Acids Res. 45, D555-D559 (2017).

20. Crosa, J. H. \& Walsh, C. T. Genetics and assembly line enzymology of siderophore biosynthesis in bacteria. Microbiol. Mol. Biol. Rev. 66, 223-249 (2002).

21. Gerlt, J. A. et al. Enzyme function initiative-enzyme similarity tool (EFI-EST): a web tool for generating protein sequence similarity networks. Biochim. Biophys. Acta Proteins Proteom. 1854, 1019-1037 (2015).

22. Chevrette, M. G. et al. SANDPUMA: ensemble predictions of nonribosomal peptide chemistry reveal biosynthetic diversity across Actinobacteria. Bioinformatics 33, 3202-3210 (2017).

23. Tietz, J. I. et al. A new genome-mining tool redefines the lasso peptide biosynthetic landscape. Nat. Chem. Biol. 13, 470-478 (2017). 
24. Cochrane, S. A. \& Vederas, J. C. Lipopeptides from Bacillus and Paenibacillus spp.: a gold mine of antibiotic candidates. Med. Res. Rev. 36, 4-31 (2016).

25. Huang, E. \& Yousef, A. E. The lipopeptide antibiotic paenibacterin binds to the bacterial outer membrane and exerts bactericidal activity through cytoplasmic membrane damage. Appl. Environ. Microbiol. 80, 2700-2704 (2014).

26. Jiang, W., Bikard, D., Cox, D., Zhang, F. \& Marraffini, L. A. RNA-guided editing of bacterial genomes using CRISPR-Cas systems. Nat. Biotechnol. 31, 233-239 (2013).

27. Altenbuchner, J. Editing of the Bacillus subtilis genome by the CRISPR-Cas9 system. Appl. Environ. Microb. 82, 5421-5427 (2016).

28. Li, Y. X., Zhong, Z., Hou, P., Zhang, W. P. \& Qian, P. Y. Resistance to nonribosomal peptide antibiotics mediated by d-stereospecific peptidases. Nat. Chem. Biol. 14, 381-387 (2018).

29. Liu, Y. Y. et al. Emergence of plasmid-mediated colistin resistance mechanism MCR-1 in animals and human beings in China: a microbiological and molecular biological study. Lancet Infect. Dis. 16, 161-168 (2016).

30. Cochrane, S. A. et al. Antimicrobial lipopeptide tridecaptin A1 selectively binds 598 to Gram-negative lipid II. Proc. Natl Acad. Sci. USA 113, 11561-11566 599 (2016).

31. Trimble, M. J., Mlynarcik, P., Kolar, M. \& Hancock, R. E. W. Polymyxin: alternative mechanisms of action and resistance. Cold Spring Harb. Perspect. Med. 6, a025288 (2016).

32. Rabanal, F. \& Cajal, Y. Recent advances and perspectives in the design and development of polymyxins. Nat. Prod. Rep. 34, 886-908 (2017).

33. Wang, R. et al. The global distribution and spread of the mobilized colistin resistance gene mcr-1. Nat. Commun. 9, 1179 (2018).

34. Weber, T. et al. AntiSMASH 3.0-a comprehensive resource for the genome mining of biosynthetic gene clusters. Nucleic Acids Res. 43, W237-W243 (2015).

35. Smoot, M. E., Ono, K., Ruscheinski, J., Wang, P. L. \& Ideker, T. Cytoscape 2.8: new features for data integration and network visualization. Bioinformatics 27, 431-432 (2010).

36. Fujii, K., Ikai, Y., Oka, H., Suzuki, M. \& Harada, K. A nonempirical method using LC/MS for determination of the absolute configuration of constituent amino acids in a peptide: combination of Marfey's method with mass spectrometry and its practical application. Anal. Chem. 69, 5146-5151 (1997).

37. DeRyke, C. A., Banevicius, M. A., Fan, H. W. \& Nicolau, D. P. Bactericidal activities of meropenem and ertapenem against extended-spectrum- $\beta$ lactamase-producing Escherichia coli and Klebsiella pneumoniae in a neutropenic mouse thigh model. Antimicrob. Agents Chemother. 51, 1481-1486 (2007).

38. National Research Council. Guide for the Care and Use of Laboratory Animals (National Academies Press, Washington, DC, 2010).

\section{Acknowledgements}

This work was generously supported by the China Ocean Mineral Resources Research and Development Association (grant no. COMRRDA17SC01 awarded to P.-Y.Q.). The authors thank Eric D. Brown from McMaster University for providing the vectorcarrying mcr-1, Xinlong An for compound isolation, and Beili Zhao and Danyang Li for their assistance in gene deletion. The authors are also grateful to Ms. Alice Cheung for English editing.

\section{Author contributions}

Y.-X.L., Z.Z., and W.-P.Z. performed the bioinformatics analysis and the chemical and biochemical experiments. All authors were involved in analyzing and discussing the results. P.-Y.Q., Y.-X.L., and Z.Z. designed the study and prepared the manuscript.

\section{Additional information}

Supplementary Information accompanies this paper at https://doi.org/10.1038/s41467 018-05781-6.

Competing interests: The authors are listed as inventors in a provisional patent application filed by the Hong Kong University of Science and Technology, which covers brevicidine, laterocidine, and their derivatives for the treatment of bacterial infections.

Reprints and permission information is available online at http://npg.nature.com/ reprintsandpermissions/

Publisher's note: Springer Nature remains neutral with regard to jurisdictional claims in published maps and institutional affiliations.

(c) (i) Open Access This article is licensed under a Creative Commons Attribution 4.0 International License, which permits use, sharing, adaptation, distribution and reproduction in any medium or format, as long as you give appropriate credit to the original author(s) and the source, provide a link to the Creative Commons license, and indicate if changes were made. The images or other third party material in this article are included in the article's Creative Commons license, unless indicated otherwise in a credit line to the material. If material is not included in the article's Creative Commons license and your intended use is not permitted by statutory regulation or exceeds the permitted use, you will need to obtain permission directly from the copyright holder. To view a copy of this license, visit http://creativecommons.org/ licenses/by/4.0/.

(C) The Author(s) 2018 